\title{
Prenatal and perinatal factors and risk of eating disorders
}

Cite this article: Larsen JT, Bulik CM, Thornton LM, Koch SV, Petersen L (2021). Prenatal and perinatal factors and risk of eating disorders. Psychological Medicine 51, 870-880. https://doi.org/10.1017/

S0033291719003945

Received: 29 April 2019

Revised: 24 October 2019

Accepted: 10 December 2019

First published online: 8 January 2020

Key words:

Anorexia nervosa; anxiety disorder; bulimia nervosa; eating disorder not otherwise specified; eating disorders; epidemiology; depressive disorders; obsessive-compulsive disorder; perinatal risk factors; prenatal risk factors

Author for correspondence:

Janne Tidselbak Larsen,

E-mail: jtl@econ.au.dk

\author{
Janne Tidselbak Larsen ${ }^{1,2,3}$ (D), Cynthia M. Bulik",5,6 (D), Laura M. Thornton ${ }^{4}$ (D), \\ Susanne Vinkel Koch ${ }^{7,8}$ (D) and Liselotte Petersen ${ }^{1,2,3}$ (iD) \\ ${ }^{1}$ National Centre for Register-based Research, Aarhus BSS, Aarhus University, Aarhus, Denmark; ${ }^{2}$ Lundbeck \\ Foundation Initiative for Integrative Psychiatric Research (iPSYCH), Aarhus University, Aarhus, Denmark; ${ }^{3}$ Centre \\ for Integrated Register-based Research (CIRRAU), Aarhus University, Aarhus, Denmark; ${ }^{4}$ Department of Psychiatry, \\ University of North Carolina at Chapel Hill, Chapel Hill, North Carolina; ${ }^{5}$ Department of Nutrition, University of \\ North Carolina at Chapel Hill, Chapel Hill, North Carolina; ${ }^{6}$ Department of Medical Epidemiology and Biostatistics, \\ Karolinska Institutet, Stockholm, Sweden; ${ }^{7}$ Mental Health Centre for Child and Adolescent Psychiatry, Copenhagen \\ Region, Copenhagen, Denmark and ${ }^{8}$ Institute of Clinical Medicine, Faculty of Health Sciences, University of \\ Copenhagen, Copenhagen, Denmark
}

\begin{abstract}
Background. Among the most disabling and fatal psychiatric illnesses, eating disorders (EDs) often manifest early in life, which encourages investigations into in utero and perinatal environmental risk factors. The objective of this study was to determine whether complications during pregnancy and birth and perinatal conditions are associated with later eating disorder risk in offspring and whether these associations are unique to EDs.

Methods. All individuals born in Denmark to Danish-born parents 1989-2010 were included in the study and followed from their $6^{\text {th }}$ birthday until the end of 2016. Exposure to factors related to pregnancy, birth, and perinatal conditions was determined using national registers, as were hospital-based diagnoses of anorexia nervosa (AN), bulimia nervosa, and eating disorder not otherwise specified during follow-up. For comparison, diagnoses of depressive, anxiety, and obsessive-compulsive disorders were also included. Cox regression was used to compare hazards of psychiatric disorders in exposed and unexposed individuals.

Results. 1167043 individuals were included in the analysis. We found that similar to the comparison disorders, prematurity was associated with increased eating disorder risk. Conversely, patterns of increasing risks of EDs, especially in AN, with increasing parental ages differed from the more $\mathrm{U}$-shaped patterns observed for depressive and anxiety disorders. Conclusions. Our results suggest that pregnancy and early life are vulnerable developmental periods when exposures may influence offspring mental health, including eating disorder risk, later in life. The results suggest that some events pose more global transdiagnostic risk whereas other patterns, such as increasing parental ages, appear more specific to EDs.
\end{abstract}

\section{Introduction}

Exposures in the prenatal and early developmental periods are thought to affect neural development and have been identified as risk factors for a range of psychiatric disorders (Nosarti et al., 2012). Among the most severe and fatal psychiatric illnesses (Chesney, Goodwin, \& Fazel, 2014), eating disorders (EDs) generally occur early in life (Zerwas et al., 2015), which points investigations of potential environmental risks towards a focus on factors operating early in life. Many psychiatric disorders appear to be influenced by pre- and perinatal factors, whereas the evidence for similar patterns in EDs is contradictory.

Twin-based heritability estimates range from $48 \%$ to $74 \%$ for anorexia nervosa (AN) (Bulik et al., 2006, 2010; Dellava, Thornton, Lichtenstein, Pedersen, \& Bulik, 2011; Kipman, Gorwood, Mouren-Simeoni, \& Ades, 1999; Klump, Miller, Keel, McGue, \& Iacono, 2001; Kortegaard, Hoerder, Joergensen, Gillberg, \& Kyvik, 2001; Wade, Bulik, Neale, \& Kendler, 2000), and $55 \%$ to $62 \%$ for bulimia nervosa (BN) (Bulik, Sullivan, \& Kendler, 1998; Bulik et al., 2010; Kortegaard et al., 2001; Trace et al., 2013), whereas single-nucleotide polymorphism-based heritability of AN has been estimated at 20\% (Duncan et al., 2017). That genetic variation seems to explain some, but not all, of the variation in EDs encourages exploration of other factors in ED etiology, including the associations between in utero and perinatal environments with ED development.

Two studies reported that higher paternal age was associated with increased risk of AN and EDs in general (Javaras et al., 2017; McGrath et al., 2014).

A review and meta-analysis investigated obstetric factors and ED risk (Krug, Taborelli, Sallis, Treasure, \& Micali, 2013). Of the six studies eligible for meta-analysis, five reported nonsignificant associations for vaginal instrumental delivery and prematurity in AN. Another 
systematic review reported that among numerous factors that have been associated with ED risk, only prematurity had been replicated across ED samples and only for AN (Raevuori, Linna, \& Keski-Rahkonen, 2014).

Two reviews on $\mathrm{BN}$ found no replicated perinatal risk factors, partly due to a few studies and incomparable exposure measures (Krug et al., 2013; Raevuori et al., 2014). A birth cohort study on self-reported lifetime BN did not find any associations with birth characteristics (Nicholls, Statham, Costa, Micali, \& Viner, 2016). To our knowledge, no studies have specifically evaluated the associations between pre- or perinatal factors and eating disorder not otherwise specified (EDNOS).

Thus, the conflicting findings across samples strongly encourage large-scale studies to provide more definitive results. The Danish national registers include information on the entire population, free of recall and selection bias, and provide unique opportunities to study even rare conditions. This study investigates and compares associations among a wide range of prenatal and perinatal factors and the risk of AN, BN, EDNOS, and, for comparison, other psychiatric disorders, in a large nationwide sample of both males and females.

\section{Methods}

\section{Study population}

All Danish citizens are assigned a unique identification number which is used as a personal identifier in all national registers and makes the accurate linkage between registers possible (Pedersen, 2011). Using the nationwide Danish Civil Registration System (Pedersen, 2011), we identified all individuals born in Denmark between 1 January 1989 and 31 December 2010, to parents also born in Denmark. Individuals who died or emigrated before their $6^{\text {th }}$ birthday were excluded from the study.

\section{Eating disorders}

All contacts to Danish hospitals are recorded in the Danish National Patient Register (NPR) (Lynge, Sandegaard, \& Rebolj, 2011) and the Danish Psychiatric Central Research Register (Mors, Perto, \& Mortensen, 2011). Inpatient contacts have been registered in the NPR since 1977 and in the Psychiatric Central Research Register since 1969. Both registers have included outpatient contacts since 1995. The International Classification of Diseases, $10^{\text {th }}$ revision (ICD-10) has been the diagnostic system used in Denmark since January 1994. Prior to that, the International Classification of Diseases, $8^{\text {th }}$ revision (ICD-8) was used.

The outcomes of interest were ICD-10 diagnoses of AN (F50.0, F50.1), BN (F50.2, F50.3), and EDNOS (F50.8, F50.9). For comparison, we also included diagnoses of depressive disorders (F32, F33), anxiety disorders (F40, F41), and obsessivecompulsive disorder (OCD) (F42). These disorders were chosen due to their symptomatic overlap with EDs.

Date of onset was defined as the admission date of the first occurrence of an in- or outpatient contact recorded in the NPR or the Psychiatric Central Research Register with each diagnosis of interest, irrespective of other previously received diagnoses. Only contacts after age 6 were included to reduce diagnostic misclassification of, for example, feeding disorders in infancy and childhood.

\section{Prenatal and perinatal factors}

Birth characteristics and pre- and perinatal factors were defined using information from various registers. Details on definitions and categories are presented in Table 1.

Pregnancy complications were defined by identifying maternal diagnoses of hemorrhage, placental disorders, amniotic fluid disorders, genitourinary tract infections, diabetes, and hypertension in the NPR between conception and birth. Date of conception was estimated using registered gestational age in the Danish Medical Birth Register (Bliddal, Broe, Pottegard, Olsen, \& Langhoff-Roos, 2018) or, if unknown, assumed to be 280 days prior to birth. Information on smoking during pregnancy was obtained from the Medical Birth Register and has been recorded from 1991 onwards.

Parental ages at the birth of the child were calculated by subtracting the date of birth of the child from the parent's date of birth. Exposures related to the birth came from the Medical Birth Register. They included information on the following: method of delivery, gestational age, multiple births, Apgar score, birth weight, and weight for gestational age [categorized as defined by Marsal et al. (1996)].

Perinatal conditions and congenital malformations were defined as contacts to a hospital, recorded in the NPR. Perinatal conditions diagnosed within the first 28 days of life were included and were categorized as diagnoses of infections, digestive, endocrine and metabolic disorders, and other perinatal conditions (e.g. respiratory and cardiovascular disorders). Congenital malformations diagnosed within the first year were categorized as congenital malformations of the mouth or digestive system, and other congenital malformations.

Pregnancy conditions, perinatal conditions, and congenital malformations were defined using only ICD-10 diagnostic codes and therefore were available only for children born 1995 or later for pregnancy conditions and 1994 or later for perinatal conditions and congenital malformations.

\section{Statistical analysis}

Follow-up began on the $6^{\text {th }}$ birthday and ended on the date of onset, death, or emigration, or 31 December 2016, whichever came first. Using Cox proportional hazards models, we estimated hazard ratios (HRs) with 95\% confidence intervals (CIs) for each type of ED. All analyses were adjusted for sex using separate underlying hazard functions, for age as the underlying time in the Cox model, for time-dependent calendar-time (categorized in 5-year intervals starting in 1995), and time-dependent mother's history of any ED (ICD-8 306.50, 306.58, 306.59; ICD-10 F50, with date of onset occurring prior to or during follow-up defined similarly to the outcome diagnoses) in analyses of $\mathrm{AN}, \mathrm{BN}$, and EDNOS. In analyses of depressive disorders, anxiety disorders, and OCD, we adjusted for maternal history of the same disorder (depressive disorders: ICD-8 296.09, 296.29, 298.09, 300.39; ICD-10 F32, F33. Anxiety disorders: ICD-8 300.09, 300.29; ICD-10 F40, F41. OCD: ICD-8 300.39; ICD-10 F42). When the sample size in each exposure-outcome strata was adequate, we conducted analogous sex-stratified analyses.

We performed multivariable analyses adjusting birth weight, weight for gestational age, and method of delivery for multiple births, and gestational age-adjusted for genitourinary tract infection during pregnancy. This was done to account for the increased risks of low birth weights and required assistance during birth 
Table 1. Definitions of pre- and perinatal factors

\begin{tabular}{|c|c|c|c|c|}
\hline Exposure & Description & Register & ICD-10 diagnoses & Categories \\
\hline Hemorrhage & $\begin{array}{l}\text { Maternal ante- or intrapartum } \\
\text { hemorrhage between conception and } \\
\text { delivery }\end{array}$ & NPR & O20, 046, 067 & No, Yes \\
\hline Placental disorders & $\begin{array}{l}\text { Maternal placental disorders between } \\
\text { conception and delivery }\end{array}$ & NPR & O43-045 & No, Yes \\
\hline $\begin{array}{l}\text { Genitourinary tract } \\
\text { infections }\end{array}$ & $\begin{array}{l}\text { Maternal genitourinary tract infections } \\
\text { between conception and delivery }\end{array}$ & NPR & 023 & No, Yes \\
\hline Diabetes & $\begin{array}{l}\text { Maternal diabetes mellitus between } \\
\text { conception and delivery }\end{array}$ & NPR & 024 & No, Yes \\
\hline Smoking & Maternal smoking during pregnancy & MBR & & No, Yes \\
\hline \multicolumn{5}{|l|}{ Birth characteristics } \\
\hline Maternal age & Age at birth of child (years) & CRS & & $<20,20-24,25-29,30-34,35-39, \geqslant 40$ \\
\hline Paternal age & Age at birth of child (years) & CRS & & $<20,20-24,25-29,30-34,35-39,40-44, \geqslant 45$ \\
\hline Birth weight & Weight in grams & MBR & & $<1500,1500-2499,2500-4499, \geqslant 4500$ \\
\hline Multiple birth & & MBR & & Singleton, twin, triplet/quadruplet \\
\hline Method of delivery & $\begin{array}{l}\text { Unassisted vaginal birth, vaginal birth } \\
\text { assisted by vacuum extraction and/or } \\
\text { forceps, or caesarian section }\end{array}$ & MBR & & Unassisted, assisted, caesarian section \\
\hline \multicolumn{5}{|l|}{ Perinatal conditions } \\
\hline Infections & $\begin{array}{l}\text { Infections specific to the perinatal period } \\
\text { within the first } 28 \text { days of life }\end{array}$ & NPR & P35-P39 & No, Yes \\
\hline $\begin{array}{l}\text { Digestive, endocrine or } \\
\text { metabolic disorders }\end{array}$ & $\begin{array}{l}\text { Digestive, endocrine and metabolic } \\
\text { disorders of fetus and newborn within } \\
\text { the first } 28 \text { days of life }\end{array}$ & NPR & P70-P78 & No, Yes \\
\hline Other perinatal conditions & $\begin{array}{l}\text { Other perinatal conditions within the first } \\
28 \text { days of life }\end{array}$ & NPR & $\begin{array}{l}\text { P10-P15, P20-P29, P50- } \\
\text { P61, P80-P83, P90-P96 }\end{array}$ & No, Yes \\
\hline Congenital malformations & & NPR & & \\
\hline $\begin{array}{l}\text { Congenital malformations } \\
\text { of the mouth or digestive } \\
\text { system }\end{array}$ & $\begin{array}{l}\text { Congenital malformations of the mouth } \\
\text { or digestive system within the first } 365 \\
\text { days of life }\end{array}$ & NPR & Q18.4-Q18.7, Q35-Q45 & No, Yes \\
\hline $\begin{array}{l}\text { Other congenital } \\
\text { malformations }\end{array}$ & $\begin{array}{l}\text { Other congenital malformations, } \\
\text { deformations and chromosomal } \\
\text { abnormalities within the first } 365 \text { days } \\
\text { of life }\end{array}$ & NPR & $\begin{array}{l}\text { Q00-Q18.3, Q18.8-Q34.9, } \\
\text { Q50-Q99 }\end{array}$ & No, Yes \\
\hline
\end{tabular}

NPR, National Patient Register; MBR, Medical Birth Register; CRS, Civil Registration System. 
occurring when delivering multiple babies and for the increased risk of preterm delivery following genitourinary tract infection (Romero, Espinoza, Chaiworapongsa, \& Kalache, 2002; Verma, Avasthi, \& Berry, 2014).

All analyses were performed in Stata version 15 using the ST suite of commands (StataCorp, 2017).

\section{Results}

The study population comprised 1167043 individuals (48.67\% females) and was followed for 13 million person-years. Frequencies for sex and exposures for the study population and for ED groups are presented in Table 2. The diagnostic groups were not mutually exclusive as persons diagnosed with multiple EDs during follow-up were included as cases in each group. A total of 231 individuals were diagnosed with both $\mathrm{AN}$ and $\mathrm{BN}$, 1321 individuals with both AN and EDNOS, 361 individuals with both BN and EDNOS, and finally, 169 individuals were diagnosed with all three types of EDs during follow-up.

Estimated HRs with 95\% CI for associations between pre- and perinatal factors and ED are presented in Table 3. The multivariable analyses with mutual adjustments for selected exposures did very little to change the conclusions and results are not shown. Sex-specific results are presented in online supplementary eTables 1 and 2. For all EDs, most results were driven by females.

Equivalent results for the comparison disorders are presented in online supplementary eTables 3 and 4. A total of 20147 individuals were diagnosed with depressive disorders during follow-up, 15205 with anxiety disorders, and 7640 with OCD.

\section{Anorexia nervosa}

Significantly increased risk of AN was observed for genitourinary tract infection [HR 1.49, 95\% CI 1.15-1.93], whereas a significantly decreased risk of AN was observed for smoking [0.83 (0.77-0.89)]. AN risk increased with increasing maternal and paternal ages at birth of child, with significantly decreased risks for parental ages below 25 years. For birth weights, only weights above $4500 \mathrm{~g}$ were associated with a decreased risk of AN [0.82 (0.67-0.99)]. Multiple birth was associated with AN risk with increased risk for both twin and triplet/quadruplet births [1.41 (1.23-1.61) and $1.92(1.03-3.57)$, respectively] compared to singleton births. Significantly increased risk of AN was observed for caesarean section compared to unassisted vaginal birth [1.09 (1.00-1.18)] and for congenital malformations of the mouth or digestive system [1.65 (1.07-2.53)]. Gestational age was inversely associated with AN risk, with increased risks for those born before term $[1.40(1.10-1.77)$ for gestational age $<33$ weeks and 1.16 (1.02-1.32) for 33-36 weeks] and decreased risk for those born after week 42 [0.87 (0.78-0.97)].

\section{Bulimia nervosa}

Increased $\mathrm{BN}$ risk was observed for increasing parental ages, with significant associations for maternal ages 30-34 years [1.12 (1.001.24)] and for paternal ages 30-34 [1.12 (1.00-1.25)] and 35-39 years [1.20 (1.05-1.37)].

Birth weight above $4500 \mathrm{~g}$ was also associated with significantly increased BN risk [1.41 (1.09-1.82)]. Being born large for gestational age was associated with increased $\mathrm{BN}$ risk [1.36 (1.11-1.68)] compared to being born average for gestational age.

\section{Eating disorder not otherwise specified}

Significantly increased risk of EDNOS was observed for hemorrhage [1.19 (1.01-1.39)]. Paternal age below 20 years was associated with a decreased risk for EDNOS [0.55 (0.32-0.94)]. Patterns similar to those of AN were also observed for cesarean section [1.18 (1.09-1.29)] and pre-term gestational ages [1.46 (1.14-1.88) for less than 33 weeks of gestation] for EDNOS. Increased EDNOS risk was observed for birth weight below $1500 \mathrm{~g}$ [1.57 (1.17-2.12)], being born small for gestational age [1.21 (1.04-1.40)], infections [1.44 (1.13-1.85)], digestive, endocrine, or metabolic disorders [1.33 (1.07-1.65)], other perinatal conditions [1.23 (1.09-1.38)], and for congenital malformations of the mouth or digestive system [2.36 (1.63-3.43)].

\section{Comparison disorders}

Multiple factors were associated with risks of depressive disorders, anxiety disorders, and OCD. Most pregnancy complications and smoking were significantly associated with increased risk of depressive and anxiety disorders, as were higher and especially lower parental ages. Some pregnancy complications and smoking were also associated with increased risk of OCD, as were higher maternal ages. Low birth weights, being born small or large for gestational age, and congenital malformations of the mouth or digestive system were also associated with increased risk of depressive disorders. Small for gestational age was also a risk factor for both anxiety disorders and OCD. Multiple birth was associated with decreased risks of depressive and anxiety disorders and increased risk of OCD. Low birth weight, low Apgar score, and prematurity were associated with an increased risk of OCD. Infections, digestive, endocrine or metabolic disorders, and other perinatal conditions were all associated with increased risks of both anxiety disorders and OCD. Congenital malformations of the mouth or digestive system were associated with increased risk of all three disorders, and other congenital malformations also with increased risk of anxiety disorders.

\section{Discussion}

In this population-based study, we investigated the associations between pre- and perinatal factors and risk of three types of ED and three comparison psychiatric disorders. Both similarities and differences emerged within EDs and when comparing to other psychiatric illnesses.

We found inverse relationships between gestational age and risks of all three EDs, with increased risks for prematurity and decreased risk for gestational age above 42 weeks, although not significant for BN. Similar patterns were seen for all three comparison disorders. Our results on gestational age are in agreement with previous findings from reviews (Krug et al., 2013; Raevuori et al., 2014). Prematurity has previously been shown to be a risk factor for various psychiatric disorders (Byrne, Agerbo, Bennedsen, Eaton, \& Mortensen, 2007; Eaton, Mortensen, Thomsen, \& Frydenberg, 2001; Monfils Gustafsson, Josefsson, Ekholm Selling, \& Sydsjö, 2009; Nosarti et al., 2012), suggesting neurodevelopmental factors and a general vulnerability following preterm birth which may lower the threshold for expression of genetic predispositions. A consequence of premature birth is the impaired maturation of the gastrointestinal tract and gut microbiota, which can affect health later in life (Arboleya et al., 2016; Henderickx, Zwittink, van Lingen, Knol, \& Belzer, 2019), and 
Table 2. Frequency of sex, pre- and perinatal factors in the cohort and in eating disorder groups

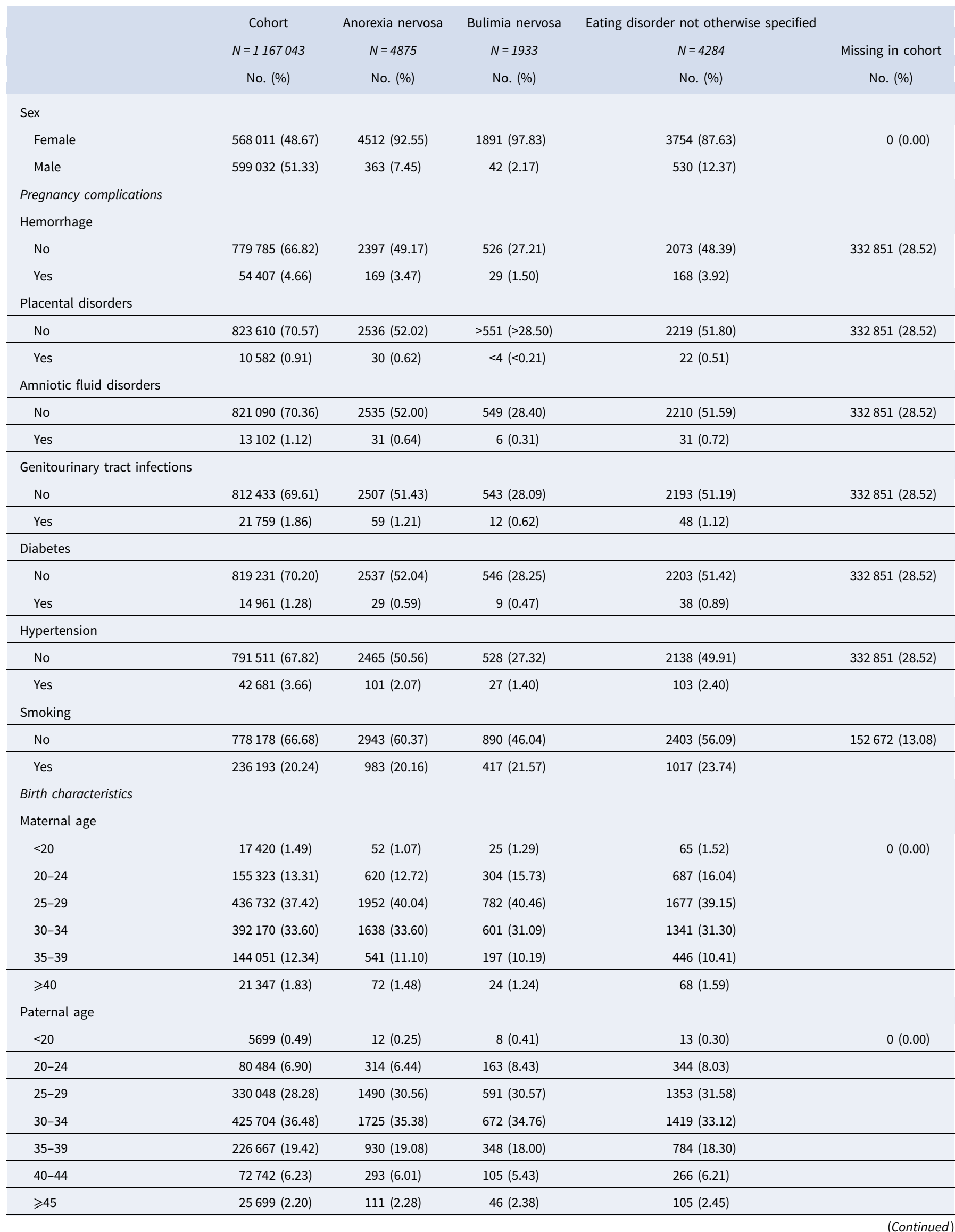


Table 2. (Continued.)

\begin{tabular}{|c|c|c|c|c|c|}
\hline & $\begin{array}{l}\text { Cohort } \\
N=1167043 \\
\text { No. }(\%)\end{array}$ & $\begin{array}{l}\text { Anorexia nervosa } \\
\qquad \begin{array}{c}N=4875 \\
\text { No. }(\%)\end{array}\end{array}$ & $\begin{array}{l}\text { Bulimia nervosa } \\
\qquad \begin{array}{c}N=1933 \\
\text { No. }(\%)\end{array}\end{array}$ & $\begin{array}{l}\text { Eating disorder not otherwise specified } \\
\qquad \begin{array}{l}N=4284 \\
\text { No. (\%) }\end{array}\end{array}$ & $\begin{array}{c}\text { Missing in cohort } \\
\text { No. (\%) }\end{array}$ \\
\hline \multicolumn{6}{|l|}{ Birth weight } \\
\hline$<1500$ & $7913(0.68)$ & $40(0.82)$ & $16(0.83)$ & $44(1.03)$ & $6832(0.59)$ \\
\hline $1500-2499$ & $48890(4.19)$ & $222(4.55)$ & $78(4.04)$ & $207(4.83)$ & \\
\hline $2500-4499$ & 1061164 (90.93) & 4469 (91.67) & 1769 (91.52) & 3892 (90.85) & \\
\hline$\geqslant 4500$ & 42244 (3.62) & $102(2.09)$ & $60(3.10)$ & $113(2.64)$ & \\
\hline \multicolumn{6}{|l|}{ Multiple birth } \\
\hline Singleton & $1123076(96.23)$ & $4648(95.34)$ & $1864(96.43)$ & $4121(96.20)$ & $30(0.00)$ \\
\hline Twin & $42791(3.67)$ & $217(4.45)$ & $64(3.31)$ & $156(3.64)$ & \\
\hline Triplet/quadruplet & $1146(0.10)$ & $10(0.21)$ & $5(0.26)$ & $7(0.16)$ & \\
\hline \multicolumn{6}{|l|}{ Method of delivery } \\
\hline Unassisted & $883950(75.74)$ & $3834(78.65)$ & $1565(80.96)$ & 3339 (77.94) & $0(0.00)$ \\
\hline Assisted & $85439(7.32)$ & $334(6.85)$ & $97(5.02)$ & $262(6.12)$ & \\
\hline Cesarean section & $197654(16.94)$ & $707(14.50)$ & $271(14.02)$ & $683(15.94)$ & \\
\hline \multicolumn{6}{|l|}{ Apgar score } \\
\hline$<7$ & $9684(0.83)$ & $50(1.03)$ & $20(1.03)$ & $47(1.10)$ & $10258(0.88)$ \\
\hline $7-9$ & $78290(6.71)$ & $310(6.36)$ & $117(6.05)$ & $259(6.05)$ & \\
\hline 10 & $1068811(91.58)$ & $4464(91.57)$ & $1786(92.40)$ & $3935(91.85)$ & \\
\hline \multicolumn{6}{|l|}{ Gestational age } \\
\hline$<33$ & $13968(1.20)$ & $69(1.42)$ & $25(1.29)$ & $64(1.49)$ & $7329(0.63)$ \\
\hline $33-36$ & $57354(4.91)$ & $243(4.98)$ & $94(4.86)$ & $209(4.88)$ & \\
\hline $37-41$ & $997610(85.48)$ & $4149(85.11)$ & $1653(85.51)$ & $3634(84.83)$ & \\
\hline$\geqslant 42$ & $90782(7.78)$ & $365(7.49)$ & $147(7.60)$ & $333(7.77)$ & \\
\hline \multicolumn{6}{|l|}{ Weight for gestational age } \\
\hline Small for gestational age & $38325(3.28)$ & $168(3.45)$ & $56(2.90)$ & $181(4.23)$ & $11622(1.00)$ \\
\hline Average for gestational age & 1072378 (91.89) & $4461(91.51)$ & $1765(91.31)$ & $3872(90.38)$ & \\
\hline Large for gestational age & $44718(3.83)$ & $168(3.45)$ & $93(4.81)$ & $170(3.97)$ & \\
\hline \multicolumn{6}{|l|}{ Perinatal conditions } \\
\hline \multicolumn{6}{|l|}{ Infections } \\
\hline No & 871506 (74.68) & $2909(59.67)$ & $726(37.56)$ & $2531(59.08)$ & $274669(23.54)$ \\
\hline Yes & $20868(1.79)$ & $57(1.17)$ & $11(0.57)$ & $65(1.52)$ & \\
\hline \multicolumn{6}{|c|}{ Digestive, endocrine or metabolic disorders } \\
\hline No & $860064(73.70)$ & $2897(59.43)$ & $723(37.40)$ & $2510(58.59)$ & $274669(23.54)$ \\
\hline 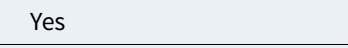 & $32310(2.77)$ & $69(1.42)$ & $14(0.72)$ & $86(2.01)$ & \\
\hline \multicolumn{6}{|l|}{ Other perinatal conditions } \\
\hline No & $776334(66.52)$ & $2655(54.46)$ & $666(34.45)$ & $2289(53.43)$ & $274669(23.54)$ \\
\hline Yes & $116040(9.94)$ & $311(6.38)$ & $71(3.67)$ & $307(7.17)$ & \\
\hline \multicolumn{6}{|l|}{ Congenital malformations } \\
\hline \multicolumn{6}{|c|}{ Congenital malformations of the mouth or digestive system } \\
\hline No & $886153(75.93)$ & $2945(60.41)$ & $>731(>37.82)$ & $2568(59.94)$ & $274669(23.54)$ \\
\hline Yes & $6221(0.53)$ & $21(0.43)$ & $<4(<0.21)$ & $28(0.65)$ & \\
\hline \multicolumn{6}{|l|}{ Other congenital malformations } \\
\hline No & $845333(72.43)$ & $2872(58.91)$ & $712(36.83)$ & $2478(57.84)$ & $274669(23.54)$ \\
\hline Yes & $47041(4.03)$ & $94(1.93)$ & $25(1.29)$ & $118(2.75)$ & \\
\hline
\end{tabular}


emerging evidence based on genetic correlations support the idea that AN perhaps should be re-conceptualized as a metabo-psychiatric disorder (Watson et al., 2019). Furthermore, preterm children have increased risk of feeding difficulties in infancy (Saigal \& Doyle, 2008) and early childhood (Hvelplund, Hansen, Koch, Andersson, \& Skovgaard, 2016), which could contribute to increased ED risk later in life, perhaps in part through a negative impact on the mother-child interaction in relation to feeding situations and food in general.

We found suggestive evidence of increasing risk of $\mathrm{AN}$, and to a lesser degree BN and EDNOS, for increasing parental ages. The increased risk for higher paternal age is in accordance with the findings from previous studies on $\mathrm{AN}$ and $\mathrm{EDs}$ in general (Javaras et al., 2017; McGrath et al., 2014). The steadily increasing relationships for EDs, and AN in particular, differ from the more U-shaped relationships observed for parental ages for both depressive and anxiety disorders in this study. The patterns for parental ages in OCD, a disorder that shares many common traits with EDs and a high genetic correlation with AN (Anttila et al., 2018; Watson et al., 2019; Yilmaz et al., 2018), were more similar to the ones observed for EDs. The increased risk of EDs in offspring of older fathers suggests an influence of age-related de novo mutations, as proposed for other types of psychiatric illness (Frans et al., 2013; Malaspina et al., 2001). However, this does not explain the increasing ED risk also seen for higher maternal age, suggesting shared genetic or environmental exposures influencing both parental reproductive age and offspring ED risk and/or environmental influence of parental age on ED risk in offspring. The associations between parental ages and EDs may, in part, be driven by higher educational attainment of older parents, as postponing reproduction until after completion of higher education is common in Denmark. Several studies have found increased incidence rates of EDs in offspring of highly educated parents (Ahrén, Chiesa, af Klinteberg, \& Koupil, 2012; Ahrén et al., 2013; Ahren-Moonga, Silverwood, Klinteberg, \& Koupil, 2009; Goodman, Heshmati, \& Koupil, 2014a; Goodman, Heshmati, Malki, \& Koupil, 2014b), and Watson et al. (2019) found positive genetic correlations between $\mathrm{AN}$ and educational attainment measures.

For maternal smoking, the decreased risk was observed for AN, but not for other disorders. A study using the Norwegian Mother and Child Cohort Study reported that the prevalence of smoking during pregnancy was non-significantly lower in mothers with AN than in mothers with other types of ED and mothers with no EDs (Lupattelli et al., 2015), which might help explain the lower AN incidence in offspring of smoking mothers in the present study. Another possible explanation for this association could be the lower prevalence of smoking during pregnancy and the higher incidence rate of AN in offspring of mothers with higher educational levels (de Wolff et al., 2019). It should be noted that smoking status was self-reported by mothers in early pregnancy and probably has lower validity than most variables included in this study due to social desirability bias (Grimm, 2010).

Multiple birth increased the risk of EDs in a dose-response manner for twin and triplet/quadruplet births compared to singleton births. This was most strongly observed in AN, which replicates the results of a Swedish study with a design analogous to the present study (Goodman et al., 2014b). A similar pattern was seen in OCD, but not in depressive or anxiety disorders, where multiple births were associated with decreased risk. The increased risk of EDs seen in offspring of multiple births could possibly be attributed to increased risk of complications during pregnancy and birth, although we found no significant differences in risk estimates when adjusting multiple birth for other birth characteristics, pointing to environmental influence linked to growing up as a twin.

$\mathrm{BN}$ incidence rates were increased for large for gestational age and (non-significantly) decreased for small for gestational age, a pattern that is opposite those observed for EDNOS, depressive disorders, and anxiety disorders with increased risks for small for gestational age. This aligns with the study by Goodman et al. (2014b), which found a positive dose-response relationship between birth weight and $\mathrm{BN}$ risk. This association might be an indicator of overweight mothers being both more likely to give birth to a large baby and to have an overweight child (Black, Sacks, Xiang, \& Lawrence, 2013; O’Reilly \& Reynolds, 2013). High body mass index in even very young girls has recently been shown to be a risk factor for later development of $\mathrm{BN}$ (Yilmaz, Gottfredson, Zerwas, Bulik, \& Micali, 2019).

For EDNOS, we identified several statistically significant associations, particularly within the perinatal conditions, suggesting a susceptibility during the perinatal period. Similar results were observed for anxiety disorders and OCD. The doubled risk seen singularly in EDNOS for children born with congenital malformations of the mouth or digestive system could suggest that some of those who are diagnosed with EDNOS, in fact, suffer from eating problems directly associated with their congenital malformations.

The observed increased risks of all three ED types (although only statistically significant for AN) for genitourinary tract infections and the significantly increased risk of EDNOS for perinatal infections are in agreement with studies that have reported increased risks of $\mathrm{AN}, \mathrm{BN}$, and EDNOS following hospitalization or medication for infection (Breithaupt et al., 2019) and an association between exposure to in utero viral infections and increased AN risk in offspring (Favaro et al., 2011). Fetal exposure to maternal infection and the resulting immune response may affect offspring neurodevelopment (Deverman \& Patterson, 2009) and later mental health, and infectious agents may be able to cross the blood-brain barrier and affect the central nervous system (Banks, Kastin, \& Broadwell, 1995). Significantly increased risks were also seen for genitourinary tract infection in all three comparison disorders and for perinatal infections in anxiety disorders and OCD, demonstrating that the infection-psychiatric illness association is not specific to EDs (Köhler-Forsberg et al., 2018).

\section{Strengths and limitations}

This nationwide population-based study included all individuals born in Denmark 1989-2010 to Danish-born parents. We were able to follow more than 1 million individuals for up to 22 years from their $6^{\text {th }}$ birthday. A main strength of the study is that all data were drawn from Danish registers, which cover all Danish citizens from birth until death. Thereby, loss to follow-up and selection bias is eliminated. Furthermore, the use of register information also eliminates most recall and reporting bias.

The register information used in this study included only hospital-based diagnoses for defining exposures and outcomes. Several of the pre- and perinatal factors were only defined or available for a subset of the cohort, and there are probable differences in their reliability. We assume that measures such as birth weight, Apgar score, and gestational age are fairly reliable measures, whereas, for example, self-reported maternal smoking is more uncertain. Diagnoses recorded in the Danish health registers are generally reliable with high positive predictive values (Bock, Bukh, Vinberg, Gether, \& Kessing, 2009; Jakobsen et al., 2005; Lauritsen et al., 2010; Phung et al., 2007). However, the validity 
Table 3. Estimated hazard ratios of eating disorders after exposure to pre- and perinatal factors

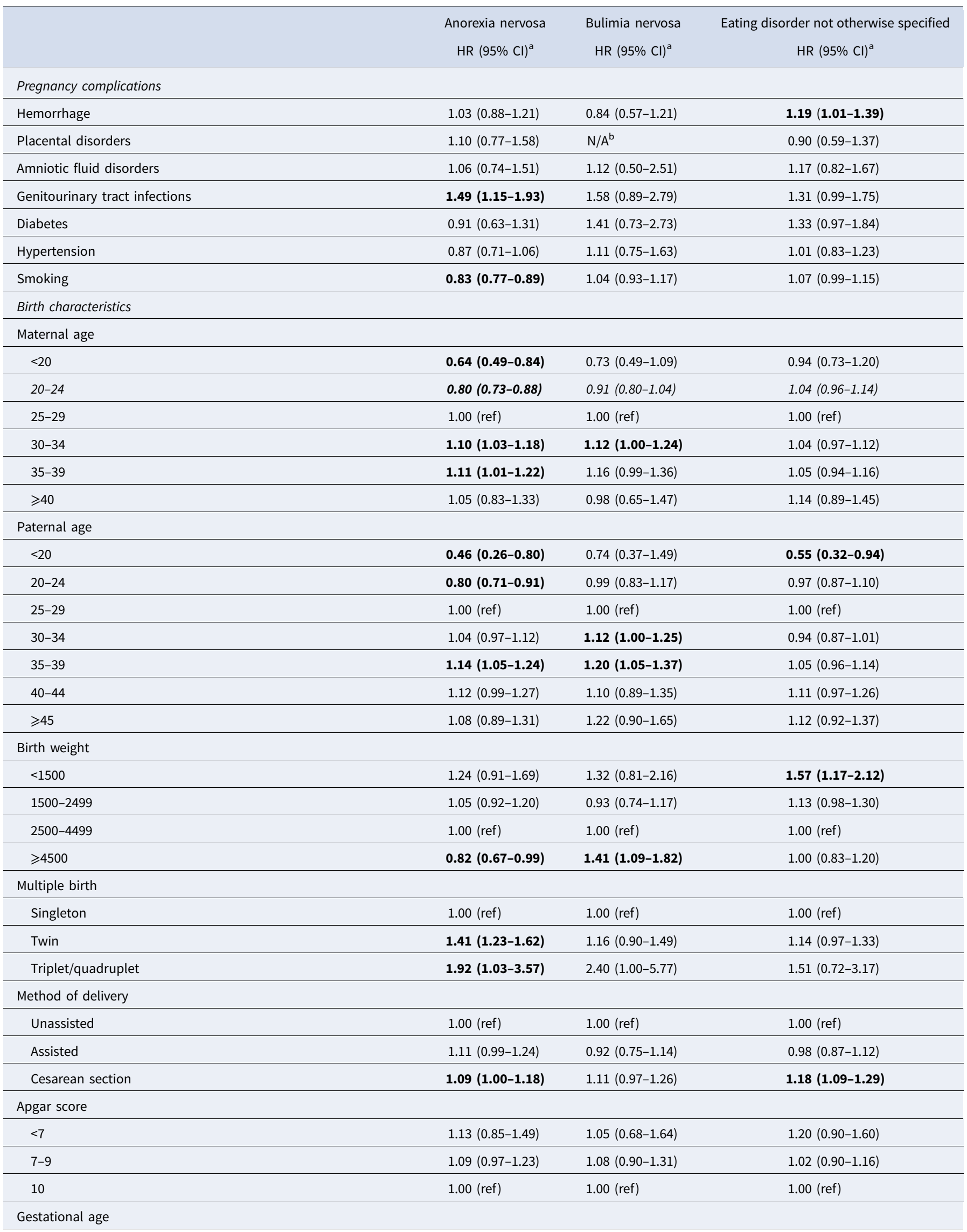


Table 3. (Continued.)

\begin{tabular}{|c|c|c|c|}
\hline & $\begin{array}{l}\text { Anorexia nervosa } \\
\qquad \operatorname{HR}(95 \% \mathrm{Cl})^{\mathrm{a}}\end{array}$ & $\begin{array}{l}\text { Bulimia nervosa } \\
\qquad \operatorname{HR}(95 \% \mathrm{CI})^{\mathrm{a}}\end{array}$ & $\begin{array}{l}\text { Eating disorder not otherwise specified } \\
\qquad \mathrm{HR}(95 \% \mathrm{Cl})^{\mathrm{a}}\end{array}$ \\
\hline$<33$ & $1.40(1.10-1.77)$ & $1.39(0.94-2.06)$ & $1.46(1.14-1.88)$ \\
\hline $33-36$ & $1.16(1.02-1.32)$ & $1.20(0.98-1.48)$ & $1.13(0.98-1.30)$ \\
\hline $37-41$ & 1.00 (ref) & 1.00 (ref) & 1.00 (ref) \\
\hline$\geqslant 42$ & $0.87(0.78-0.97)$ & $0.85(0.72-1.00)$ & $0.91(0.81-1.02)$ \\
\hline \multicolumn{4}{|l|}{ Weight for gestational age } \\
\hline Small for gestational age & $0.96(0.82-1.12)$ & $0.79(0.61-1.03)$ & $1.20(1.04-1.40)$ \\
\hline Average for gestational age & 1.00 (ref) & 1.00 (ref) & 1.00 (ref) \\
\hline Large for gestational age & $0.93(0.80-1.08)$ & $1.36(1.11-1.68)$ & $1.08(0.92-1.26)$ \\
\hline \multicolumn{4}{|l|}{ Perinatal conditions } \\
\hline Infections & $1.15(0.88-1.49)$ & $0.98(0.54-1.78)$ & $1.44(1.13-1.85)$ \\
\hline Digestive, endocrine or metabolic disorders & $0.97(0.76-1.23)$ & $0.95(0.56-1.60)$ & $1.33(1.07-1.65)$ \\
\hline Other perinatal conditions & $1.11(0.99-1.25)$ & $1.08(0.84-1.38)$ & $1.23(1.09-1.38)$ \\
\hline \multicolumn{4}{|l|}{ Congenital malformations } \\
\hline Congenital malformations of the mouth or digestive system & $1.65(1.07-2.53)$ & $N / A^{b}$ & $2.36(1.63-3.43)$ \\
\hline Other congenital malformations & $0.83(0.67-1.02)$ & $0.95(0.64-1.41)$ & $1.17(0.97-1.40)$ \\
\hline
\end{tabular}

$\mathrm{HR}$, hazard ratio; $\mathrm{Cl}$, confidence interval.

Results that are statistically significant at $\alpha=0.05$ are highlighted in bold.

${ }^{a}$ Adjusted for sex, age, calendar-time, and history of any maternal eating disorders.

${ }^{\mathrm{b}}$ Not estimated due to few exposed cases.

of the various ED diagnoses may differ: In ICD-10 there is no binge-purge AN subtype and these patients can be difficult to diagnose in a systematic way - some clinicians will diagnose them with $\mathrm{AN}$ and some with BN, depending on their weight. This could potentially bias our $\mathrm{BN}$ results toward the patterns observed for AN. However, the number of conflicting cases is probably relatively small. The ENDOS diagnosis is given to a broad spectrum of ED subtypes - patients not fulfilling all diagnostic criteria of AN or $\mathrm{BN}$, and patients with binge eating or other types of ED. How this affects our results is difficult to determine.

The Danish healthcare system is paid through taxation and is therefore free of charge for Danish citizens, including treatment in hospitals. This eliminates some differential access to healthcare, but utilization of mental health services still differs depending on factors such as socio-economic status and distance to healthcare providers (Packness et al., 2017; Packness, Halling, Simonsen, Waldorff, \& Hastrup, 2019). This may have biased our results, as individuals from a higher socio-economic background could be more likely to be diagnosed with both the outcome disorders and several of the exposure conditions. Furthermore, we were unable to capture those diagnosed only in primary care, those not seeking care, and those with subthreshold symptoms. Therefore, it is likely only the most severe cases were included, and the true incidences of both outcomes and several exposures are most likely higher than reported here.

\section{Conclusions}

Our results indicate that certain pre- and perinatal factors may influence later ED risk. The increased risks of EDs were similar to those seen for other psychiatric illnesses for prematurity and maternal genitourinary tract infection, suggesting a universal influence on neurodevelopment and later mental health. Conversely, patterns of association with parental ages and multiple birth for EDs was similar to OCD but different from those seen for other psychiatric illness, perhaps pointing to differing responses to childhood environment. Comparing ED subtypes, differences also emerged with regard to smoking during pregnancy, being born large for gestational age, and certain congenital malformations, suggesting disorder-specific vulnerabilities also within EDs. Our results encourage further replication in large samples and genetically informed studies to disentangle the potential genetic and environmental mechanisms of the associations.

Supplementary material. The supplementary material for this article can be found at https://doi.org/10.1017/S0033291719003945

Acknowledgements. This study was supported by the Lundbeck Foundation (J.T.L., L.P., grant number R248-2017-2003), (L.P., grant number R276-2018-4581); the Klarman Family Foundation (J.T.L., C.M.B, L.M.T.); and Helsefonden (J.T.L., grant no. 18-B-0154).

Conflict of interest. C.M.B. reports Shire (Scientific Advisory Board member); Idorsia (consultant); Pearson (author, royalty recipient).

\section{References}

Ahrén, J. C., Chiesa, F., af Klinteberg, B., \& Koupil, I. (2012). Psychosocial determinants and family background in anorexia nervosa - results from the Stockholm birth cohort study. International Journal of Eating Disorders, 45, 362-369.

Ahrén, J. C., Chiesa, F., Koupil, I., Magnusson, C., Dalman, C., \& Goodman, A. (2013). We are family--parents, siblings, and eating disorders in a prospective total-population study of 250000 Swedish males and females. International Journal of Eating Disorders, 46, 693-700. 
Ahren-Moonga, J., Silverwood, R., Klinteberg, B. A., \& Koupil, I. (2009). Association of higher parental and grandparental education and higher school grades with risk of hospitalization for eating disorders in females: The Uppsala birth cohort multigenerational study. American Journal of Epidemiology, 170, 566-575.

Anttila, V., Bulik-Sullivan, B., Finucane, H. K., Walters, R. K., Bras, J., Duncan, L., ... Murray, R. (2018). Analysis of shared heritability in common disorders of the brain. Science, 360, eaap8757.

Arboleya, S., Sanchez, B., Solis, G., Fernandez, N., Suarez, M. Hernandez-Barranco, A. M., ... Gueimonde, M. (2016). Impact of prematurity and perinatal antibiotics on the developing intestinal Microbiota: A functional inference study. International Journal of Molecular Sciences, 17, 649.

Banks, W. A., Kastin, A. J., \& Broadwell, R. D. (1995). Passage of cytokines across the blood-brain barrier. Neuroimmunomodulation, 2, 241-248.

Black, M. H., Sacks, D. A., Xiang, A. H., \& Lawrence, J. M. (2013). The relative contribution of prepregnancy overweight and obesity, gestational weight gain, and IADPSG-defined gestational diabetes mellitus to fetal overgrowth. Diabetes Care, 36, 56-62.

Bliddal, M., Broe, A., Pottegard, A., Olsen, J., \& Langhoff-Roos, J. (2018). The Danish medical birth register. European Journal of Epidemiology, 33, 27-36.

Bock, C., Bukh, J. D., Vinberg, M., Gether, U., \& Kessing, L. V. (2009). Validity of the diagnosis of a single depressive episode in a case register. Clinical Practice and Epidemiology in Mental Health, 5, 4.

Breithaupt, L., Köhler-Forsberg, O., Larsen, J. T., Benros, M. E., Thornton, L. M., Bulik, C. M., \& Petersen, L. (2019). Association of exposure to infections in childhood with risk of eating disorders in adolescent girls. JAMA Psychiatry, 76, 800-809.

Bulik, C. M., Sullivan, P. F., \& Kendler, K. S. (1998). Heritability of binge-eating and broadly defined bulimia nervosa. Biological Psychiatry, 44, 1210-1218.

Bulik, C. M., Sullivan, P. F., Tozzi, F., Furberg, H., Lichtenstein, P., \& Pedersen, N. L. (2006). Prevalence, heritability, and prospective risk factors for anorexia nervosa. Archives of General Psychiatry, 63, 305-312.

Bulik, C. M., Thornton, L. M., Root, T. L., Pisetsky, E. M., Lichtenstein, P., \& Pedersen, N. L. (2010). Understanding the relation between anorexia nervosa and bulimia nervosa in a Swedish national twin sample. Biological Psychiatry, 67, 71-77.

Byrne, M., Agerbo, E., Bennedsen, B., Eaton, W. W., \& Mortensen, P. B. (2007). Obstetric conditions and risk of first admission with schizophrenia: A Danish national register based study. Schizophrenia Research, 97, 51-59.

Chesney, E., Goodwin, G. M., \& Fazel, S. (2014). Risks of all-cause and suicide mortality in mental disorders: A meta-review. World Psychiatry, 13, 153-160.

Dellava, J. E., Thornton, L. M., Lichtenstein, P., Pedersen, N. L., \& Bulik, C. M. (2011). Impact of broadening definitions of anorexia nervosa on sample characteristics. Journal of Psychiatric Research, 45, 691-698.

Deverman, B. E., \& Patterson, P. H. (2009). Cytokines and CNS development. Neuron, 64, 61-78.

de Wolff, M. G., Backhausen, M. G., Iversen, M. L., Bendix, J. M., Rom, A. L., \& Hegaard, H. K. (2019). Prevalence and predictors of maternal smoking prior to and during pregnancy in a regional Danish population: A crosssectional study. Reproductive Health, 16, 82.

Duncan, L., Yilmaz, Z., Gaspar, H., Walters, R., Goldstein, J., Anttila, V., ... Bulik, C. M. (2017). Significant locus and metabolic genetic correlations revealed in genome-wide association study of anorexia nervosa. American Journal of Psychiatry, 174, 850-858.

Eaton, W. W., Mortensen, P. B., Thomsen, P. H., \& Frydenberg, M. (2001). Obstetric complications and risk for severe psychopathology in childhood. Journal of Autism and Developmental Disorders, 31, 279-285.

Favaro, A., Tenconi, E., Ceschin, L., Zanetti, T., Bosello, R., \& Santonastaso, P. (2011). In utero exposure to virus infections and the risk of developing anorexia nervosa. Psychological Medicine, 41, 2193-2199.

Frans, E. M., Sandin, S., Reichenberg, A., Langstrom, N., Lichtenstein, P., McGrath, J. J., \& Hultman, C. M. (2013). Autism risk across generations: A population-based study of advancing grandpaternal and paternal age. JAMA Psychiatry, 70, 516-521.

Goodman, A., Heshmati, A., \& Koupil, I. (2014a). Family history of education predicts eating disorders across multiple generations among 2 million Swedish males and females. PloS One, 9, e106475.
Goodman, A., Heshmati, A., Malki, N., \& Koupil, I. (2014b). Associations between birth characteristics and eating disorders across the life course: Findings from 2 million males and females born in Sweden, 1975-1998. American Journal of Epidemiology, 179, 852-863.

Grimm, P. (2010). Social desirability bias. In J. N. Sheth and N. Malhotra (Eds.), Wiley international encyclopedia of marketing (Vol. 2). USA: John Wiley \& Sons, Ltd.

Henderickx, J. G. E., Zwittink, R. D., van Lingen, R. A., Knol, J., \& Belzer, C. (2019). The preterm gut microbiota: An inconspicuous challenge in nutritional neonatal care. Frontiers in cellular and infection microbiology, 9, 85.

Hvelplund, C., Hansen, B. M., Koch, S. V., Andersson, M., \& Skovgaard, A. M. (2016). Perinatal risk factors for feeding and eating disorders in children aged 0 to 3 years. Pediatrics, 137, e20152575.

Jakobsen, K. D., Frederiksen, J. N., Hansen, T., Jansson, L. B., Parnas, J., \& Werge, T. (2005). Reliability of clinical ICD-10 schizophrenia diagnoses. Nordic Journal of Psychiatry, 59, 209-212.

Javaras, K. N., Rickert, M. E., Thornton, L. M., Peat, C. M., Baker, J. H., Birgegard, A., ... D’Onofrio, B. M. (2017). Paternal age at childbirth and eating disorders in offspring. Psychological Medicine, 47, 576-584.

Kipman, A., Gorwood, P., Mouren-Simeoni, M. C., \& Ades, J. (1999). Genetic factors in anorexia nervosa. European Psychiatry, 14, 189-198.

Klump, K. L., Miller, K. B., Keel, P. K., McGue, M., \& Iacono, W. G. (2001). Genetic and environmental influences on anorexia nervosa syndromes in a population-based twin sample. Psychological Medicine, 31, 737-740.

Köhler-Forsberg, O., Petersen, L., Gasse, C., Mortensen, P. B., Dalsgaard, S., Yolken, R. H., ... Benros, M. E. (2018). A nationwide study in Denmark of the association between treated infections and the subsequent risk of treated mental disorders in children and adolescents. JAMA Psychiatry, 76, 271-279.

Kortegaard, L. S., Hoerder, K., Joergensen, J., Gillberg, C., \& Kyvik, K. O. (2001). A preliminary population-based twin study of self-reported eating disorder. Psychological Medicine, 31, 361-365.

Krug, I., Taborelli, E., Sallis, H., Treasure, J., \& Micali, N. (2013). A systematic review of obstetric complications as risk factors for eating disorder and a meta-analysis of delivery method and prematurity. Physiology \& Behavior, 109, 51-62.

Lauritsen, M. B., Jorgensen, M., Madsen, K. M., Lemcke, S., Toft, S., Grove, J., ... Thorsen, P. (2010). Validity of childhood autism in the Danish Psychiatric Central Register: Findings from a cohort sample born 19901999. Journal of Autism and Developmental Disorders, 40, 139-148.

Lupattelli, A., Spigset, O., Torgersen, L., Zerwas, S., Hatle, M., Reichborn-Kjennerud, T., ... Nordeng, H. (2015). Medication Use before, during, and after pregnancy among women with eating disorders: A study from the Norwegian Mother and Child Cohort Study. PloS One, 10, e0133045.

Lynge, E., Sandegaard, J. L., \& Rebolj, M. (2011). The Danish national patient register. Scandinavian Journal of Public Health, 39, 30-33.

Malaspina, D., Harlap, S., Fennig, S., Heiman, D., Nahon, D., Feldman, D., \& Susser, E. S. (2001). Advancing paternal age and the risk of schizophrenia. Archives of General Psychiatry, 58, 361-367.

Marsal, K., Persson, P. H., Larsen, T., Lilja, H., Selbing, A., \& Sultan, B. (1996). Intrauterine growth curves based on ultrasonically estimated foetal weights. Acta Paediatrica, 85, 843-848.

McGrath, J. J., Petersen, L., Agerbo, E., Mors, O., Mortensen, P. B., \& Pedersen, C. B. (2014). A comprehensive assessment of parental age and psychiatric disorders. JAMA Psychiatry, 71, 301-309.

Monfils Gustafsson, W., Josefsson, A., Ekholm Selling, K., \& Sydsjö, G. (2009). Preterm birth or foetal growth impairment and psychiatric hospitalization in adolescence and early adulthood in a Swedish population-based birth cohort. Acta Psychiatrica Scandinavica, 119, 54-61.

Mors, O., Perto, G. P., \& Mortensen, P. B. (2011). The Danish psychiatric central research register. Scandinavian Journal of Public Health, 39, 54-57.

Nicholls, D., Statham, R., Costa, S., Micali, N., \& Viner, R. M. (2016). Childhood risk factors for lifetime bulimic or compulsive eating by age 30 years in a British national birth cohort. Appetite, 105, 266-273.

Nosarti, C., Reichenberg, A., Murray, R. M., Cnattingius, S., Lambe, M. P., Yin, L., ... Hultman, C. M. (2012). Preterm birth and psychiatric disorders in young adult life. Archives of General Psychiatry, 69, E1-E8.

O'Reilly, J. R., \& Reynolds, R. M. (2013). The risk of maternal obesity to the long-term health of the offspring. Clinical Endocrinology, 78, 9-16. 
Packness, A., Halling, A., Simonsen, E., Waldorff, F. B., \& Hastrup, L. H. (2019). Are perceived barriers to accessing mental healthcare associated with socioeconomic position among individuals with symptoms of depression? Questionnaire-results from the Lolland-Falster Health Study, a rural Danish population study. BMJ Open, 9, e023844.

Packness, A., Waldorff, F. B., Christensen, R. D., Hastrup, L. H., Simonsen, E., Vestergaard, M., \& Halling, A. (2017). Impact of socioeconomic position and distance on mental health care utilization: A nationwide Danish follow-up study. Social Psychiatry and Psychiatric Epidemiology, 52, 14051413.

Pedersen, C. B. (2011). The danish civil registration system. Scandinavian Journal of Public Health, 39, 22-25.

Phung, T. K., Andersen, B. B., Hogh, P., Kessing, L. V., Mortensen, P. B., \& Waldemar, G. (2007). Validity of dementia diagnoses in the Danish hospital registers. Dementia and Geriatric Cognitive Disorders, 24, 220-228.

Raevuori, A., Linna, M. S., \& Keski-Rahkonen, A. (2014). Prenatal and perinatal factors in eating disorders: A descriptive review. International Journal of Eating Disorders, 47, 676-685.

Romero, R., Espinoza, J., Chaiworapongsa, T., \& Kalache, K. (2002). Infection and prematurity and the role of preventive strategies. Seminars in Neonatology, 7, 259-274.

Saigal, S., \& Doyle, L. W. (2008). An overview of mortality and sequelae of preterm birth from infancy to adulthood. Lancet, 371, 261-269.

StataCorp (2017). Stata statistical software: Release 15. College Station, TX: StataCorp LLC.
Trace, S. E., Thornton, L. M., Baker, J. H., Root, T. L., Janson, L. E., Lichtenstein, P., ... Bulik, C. M. (2013). A behavioral-genetic investigation of bulimia nervosa and its relationship with alcohol use disorder. Psychiatry Research, 208, 232-237.

Verma, I., Avasthi, K., \& Berry, V. (2014). Urogenital infections as a risk factor for preterm labor: A hospital-based case-control study. Journal of Obstetrics and Gynaecology of India, 64, 274-278.

Wade, T. D., Bulik, C. M., Neale, M., \& Kendler, K. S. (2000). Anorexia nervosa and major depression: Shared genetic and environmental risk factors. American Journal of Psychiatry, 157, 469-471.

Watson, H. J., Yilmaz, Z., Thornton, L. M., Hubel, C., Coleman, J. R. I., Gaspar, H. A., ... Bulik, C. M. (2019). Genome-wide association study identifies eight risk loci and implicates metabo-psychiatric origins for anorexia nervosa. Nature Genetics, 51, 1207-1214.

Yilmaz, Z., Gottfredson, N. C., Zerwas, S. C., Bulik, C. M., \& Micali, N. (2019). Developmental premorbid body mass index trajectories of adolescents with eating disorders in a longitudinal population cohort. Journal of the American Academy of Child and Adolescent Psychiatry, 58, 191-199.

Yilmaz, Z., Halvorsen, M., Bryois, J., Yu, D., Thornton, L. M., Zerwas, S., ... Crowley, J. J. (2018). Examination of the shared genetic basis of anorexia nervosa and obsessive-compulsive disorder. Molecular Psychiatry. [Epub ahead of print]

Zerwas, S., Larsen, J. T., Petersen, L., Thornton, L. M., Mortensen, P. B., \& Bulik, C. M. (2015). The incidence of eating disorders in a Danish register study: Associations with suicide risk and mortality. Journal of Psychiatric Research, 65, 16-22. 